\title{
Effects of deposit-feeder gut passage and fecal pellet encapsulation on germination of dinoflagellate resting cysts
}

\author{
A. Kremp ${ }^{1,3, *}$, D. H. Shull ${ }^{2}$, D. M. Anderson ${ }^{1}$ \\ ${ }^{1}$ Biology Department, Woods Hole Oceanographic Institution, Woods Hole, Massachusetts 02543, USA \\ ${ }^{2}$ Department of Environmental Sciences, Western Washington University, Bellingham, Washington 98225, USA \\ ${ }^{3}$ Present address: University of Helsinki, Tvärminne Zoological Station, 00190 Hanko, Finland
}

\begin{abstract}
Many species of dinoflagellates spend much of their lives buried in sediments as resting cysts. While on the bottom, cysts may pass through the guts of deposit feeders before conditions become favorable for germination. Little is known, however, about how dinoflagellate cysts are affected by deposit-feeder digestion, fecal pellet formation, and translocation within the sediment column. To answer the question of whether gut passage or pelletization reduces cyst germination, we fed cysts of the dinoflagellate Scrippsiella lachrymosa to 3 polychaete deposit feeders, Capitella sp., Streblospio benedicti, and Polydora cornuta. Fecal pellets of these species have different morphologies and represent a wide range of pellet robustness. To examine the effects of longer gut-passage times, cysts were incubated in the digestive fluids of the polychaete Arenicola marina for up to $24 \mathrm{~h}$, and monitored to determine germination success. Cysts were remarkably resistant to digestion by deposit-feeding polychaetes, and were capable of germinating even within the robust fecal pellets of Capitella. In fact, cysts were more likely to germinate within fecal pellets of Capitella than outside those pellets. Thus, pellets may be favorable environments for germination of resting cysts. Our data suggest that deposit-feeder gut passage and pelletization do not substantially reduce germination of dinoflagellate cysts in the field, and may even enhance it.
\end{abstract}

KEY WORDS: Dinoflagellate cysts $\cdot$ Deposit feeder $\cdot$ Germination $\cdot$ Fecal pellets $\cdot$ Scrippsiella lachrymosa

\section{INTRODUCTION}

Benthic resting stages can play a significant role in the population biology of phytoplanktonic organisms. Germination and formation of resting stages represent gains to a population through seeding (Anderson \& Wall 1979, Imai et al. 1991, Hansson 1996, Itakura et al. 1997), and losses through sedimentation, respectively (Smetacek 1985, Heiskanen 1993, Head et al. 1999). Both processes are important variables in the population dynamics of species with resting stages, as both are regulated by a number of endogenous and environmental factors that may determine their outcome.
In dinoflagellates, most studies of life cycle and population dynamics have focused on the mechanisms of encystment and excystment and the factors that regulate these life-cycle transitions (e.g. Anderson et al. 1982, Binder \& Anderson 1987, Blanco 1995, Rengefors \& Anderson 1998, Nuzzo \& Montresor 1999, Sgrosso et al. 2001). The time interval in the sediment and the conditions experienced there by the cysts have received little attention with respect to possible effects on germination and seeding, although many dinoflagellates spend considerably more time as benthic resting cysts in the sediment than as planktonic cells in the water column. Generally, the thick and resistant wall, which is char- 
acteristic for a dinoflagellate resting cyst (Kokinos \& Anderson 1995), is assumed to shield the organism from environmental influences in the sediment (Dale 1983). Decades-old cysts that are fully capable of germination (Huber \& Nipkow 1923, Lewis et al. 1999, McQuoid et al. 2002) are impressive examples of such protection.

Despite this protection, cysts may be subject to a variety of benthic processes that could affect their germination and, thus, the dynamics of the planktonic population (Keafer et al. 1992). Bioturbation, for example, may lead to burial and loss of viable cysts to deep anoxic layers. On the other hand, cysts may be returned to the sediment surface and exposed to germination cues through the activity of benthic organisms. Studies on seed banks of zooplankton (Kearns et al. 1996, Caceres \& Hairston 1998, Albertsson \& Leonardsson 2001), phytoplankton (Ståhl-Delbanco \& Hansson 2002) and macrophytes (Luckenbach \& Orth 1999) have examined positive and negative effects of bioturbation on recruitment, and shown that the success of seeding can depend on the structure and composition of the invertebrate community. Furthermore, dinoflagellate cyst assemblages in bottom sediments may be affected by predation. As dinoflagellate cysts contain starch and other nutritious accumulation products, they could serve as food for specialized predators (Persson 2000). Persson \& Rosenberg (2003) found that selective feeding of the benthic fauna results in a reduction of cysts with calcareous and nonfossilizable walls in cyst assemblages.

Besides such quantitative gains and losses, dinoflagellate cyst populations may also experience conditions in the sediment that affect cyst viability and germination directly. In situ germination studies, for example, report that only a fraction of the seed stock at the sediment surface would germinate, despite favorable ambient conditions (Ishikawa \& Taniguchi 1996, Kremp 2000). This loss of capability for germination in a part of the cyst population may be attributed to cyst age or long-term effects of hydrogen sulfide associated with temporary anoxia (Montani et al. 1995, Kremp \& Anderson 2000). Recently, the effects of deposit-feeding invertebrates have been discussed as possible causes of reduced cyst germination (Ichimi \& Montani 2001, Giangrande et al. 2002). Deposit feeders are the dominant trophic group of the benthos in most coastal areas, particularly in muddy sediments (Rhoads \& Young 1970) where cysts usually accumulate. They have ingestion rates that average about 3 body weights per day (Cammen 1980). Consequently, particles, including dinoflagellate cysts, are likely to pass through deposit-feeder guts several times before conditions become favorable for germination. In fact, dinoflagellate cysts have been repeatedly found in fecal pellets of polychaetes and bivalves (Ichimi \& Montani 2001, Tsujino et al. 2002). As deposit-feeder guts contain high concentrations of surfactants and hydrolytic enzymes (Mayer et al. 1997), the question arises as to whether gut passage could affect cyst viability due to physical or chemical changes experienced during digestion. Several studies have examined the viability of cysts from feces of polychaetes and bivalves, but with conflicting results. Whereas Giangrande et al. (2002) reported that germination success was reduced in cysts of Scrippsiella ramonii after gut passage, Ichimi \& Montani (2002) found no effect in cysts of closely related S. trochoidea, as did Tsujino et al. (2002) for cysts of Alexandrium spp. The latter authors hypothesized, however, that cysts enclosed in pellets would ultimately not be able to germinate successfully due to a hostile microclimate of the pellet and the mechanical barrier of the pellet wall. Thus, overall germination of cyst populations could still be reduced by deposit feeders if a high proportion of cysts were enclosed in pellets (Tsujino et al. 2002), with substantial consequences for the recruitment of a dinoflagellate species.

The present study investigates the effects of depositfeeder gut passage on cyst viability in controlled laboratory experiments, using cysts of known origin and history. We tested cyst germination of Scrippsiella lachrymosa, a coastal, cyst-producing dinoflagellate, following ingestion by 3 different species of depositfeeding polychaetes, which show among the highest enzyme activities and surfactant concentrations found so far among deposit feeders (Mayer et al. 1997). The deposit feeders produced fecal pellets with different levels of durability and had different gut-passage times, allowing us to directly test the effects of pelletization and gut passage on cyst germination. To examine the effects of even longer gut-passage times on cyst viability, we exposed cysts to deposit-feeder digestive fluids in vitro.

\section{MATERIALS AND METHODS}

Cyst production. Cysts of Scrippsiella lachrymosa were obtained by incubating exponentially growing cells of a strain in which high encystment success has been demonstrated (Olli \& Anderson 2001), in f/2 enriched Vineyard Sound water containing 1/8 of the full-strength nitrate concentrations, at $15^{\circ} \mathrm{C}, 400 \mu \mathrm{mol}$ $\mathrm{m}^{-2} \mathrm{~s}^{-1}$ irradiance and a 14:10 h light:dark cycle. Within $15 \mathrm{~d}$, large amounts of oval cysts were formed and deposited on the bottom of the culture tubes. Cysts were harvested and stored in the dark at $4^{\circ} \mathrm{C}$ until needed.

Gut passage and germination. Specimens of 3 polychaete species, Polydora cornuta, Streblospio bene- 
dicti, and Capitella sp., were collected from a tidal flat at Sippewisset Marsh in July 2002. For the first feeding experiment, we used $S$. benedicti collected from Savin Hill Cove in Boston Harbor. These polychaetes were chosen because they are cosmopolitan and often abundant members of benthic communities, and they produce different kinds of fecal pellets. P. cornuta produces loose, unpelletized feces. $S$. benedicti produces slender cylindrical pellets. Capitella sp. produces extremely durable, compact, prolate spheroidal pellets. These polychaetes were collected by washing samples of the uppermost $2 \mathrm{~cm}$ of sediment through a $1 \mathrm{~mm}$ mesh sieve, and 10 to 15 individuals of each species were isolated from the retained fraction and placed into separate petri dishes containing 2 teaspoons of freeze-thawed Sippewisset Marsh mud and GF/F filtered seawater. Worms were allowed to acclimate at $15^{\circ} \mathrm{C}$ and were subsequently fed sediment containing S. lachrymosa cysts. We used 2-mo old cysts to ensure that they had completed their mandatory dormancy period (Olli \& Anderson 2001), and were physiologically capable of germination. For the experiments with $S$. benedicti and $P$. cornuta, cysts were pipetted onto the sediment surface in the worms' feeding areas. Feeding on cysts was observed under a dissecting microscope, and fecal material was sampled by pipette. Uningested cysts in the petri dishes served as a control. For experiments with Capitella, $4 \mathrm{ml}$ of cyst suspension at a concentration of $1.5 \times 10^{4} \mathrm{cysts} \mathrm{m}^{-1}$ were evenly pipetted into the petri dishes that were then set aside in a dark box. A petri dish without worms was prepared in the same way to serve as a control. After $12 \mathrm{~h}$ of incubation at $15^{\circ} \mathrm{C}$, fecal pellets were collected for subsequent germination experiments. Fecal pellets of $S$. benedicti and Capitella, as well as loose feces of $P$. cornuta and the cyst suspensions from control treatments, were sonicated for $5 \mathrm{~s}$ using a Branson Ultrasonic probe. Approximately 30 to 40 cysts from feces of replicate worms of each species and the control treatment were then isolated into single wells of 96 -well culture plates containing $200 \mu \mathrm{l}$ of $\mathrm{f} / 2$ medium. The cysts were incubated under standard culture conditions (see above) for $7 \mathrm{~d}$, and excystment was monitored daily by counting empty and full cysts under a Zeiss IM 35 inverted microscope.

Gut fluid experiment. To simulate different gut-passage times and to study how prolonged exposure to gut fluids affects cysts, in vitro digestion experiments were conducted using digestive fluids extracted from the guts of the lugworm Arenicola marina. The gut fluids had been collected as described in Shull \& Mayer (2002) and stored at $-80^{\circ} \mathrm{C}$ until they were used for our incubation experiments with dinoflagellate cysts. For the incubations, we suspended mature Scrippsiella lachrymosa in $15 \mathrm{ml}$ centrifuge tubes containing $8 \mathrm{ml}$ of either A. marina digestive fluids or filtered seawater as control. To keep the cysts in suspension, tubes were mounted on a laboratory rotator and shaken at $125 \mathrm{rpm}$ throughout the incubations. We chose 6 incubation times, exponentially increasing from 10 to $360 \mathrm{~min}$. An additional $24 \mathrm{~h}$ incubation was also conducted. After each incubation the digestive fluids were twice washed from the cysts by centrifugation at $3500 \times g$ for $5 \mathrm{~min}$, aspiration of the fluid, and resuspension of the cyst pellet in filtered sea-water. Single cysts were then isolated into 96-well culture plates and incubated at $15^{\circ} \mathrm{C}$ for $7 \mathrm{~d}$. Culture plates were checked daily for excystment.

Germination from pellets. To test the effects of pelletization on excystment, we incubated intact fecal pellets of cyst-fed Streblospio benedicti and Capitella sp. individuals. Thirty pellets of each species, originating from approximately 8 to 11 worms, were placed into culture wells. Pellets were washed repeatedly in filtered seawater prior to isolation to avoid contamination with cysts that had not been ingested by the worms. Great care was taken during isolation to avoid any damage to the pellets. Thirty pellets that had been disaggregated by sonication were used as a pelletization control. Once placed in the $15^{\circ} \mathrm{C}$ incubator, culture plates were checked daily for swimming cells emerging in the wells. After $7 \mathrm{~d}$ of incubation, cyst germination was determined by disrupting pellets in the culture wells with the sonication probe and counting the number of empty and full cysts in the resulting debris. Empty and full control cysts in wells containing pellets that had been disrupted prior to incubation were also counted. To assess the effect of sonication on cyst germination, we conducted a germination experiment with sonicated and non-sonicated cysts. Replicate $25 \mu \mathrm{l}$ subsamples of the cyst stock, containing approximately $400 \mathrm{cysts}$, were added to $200 \mu \mathrm{l} / 2$ medium into 10 wells of a culture plate. Contents of 5 of the wells were then sonicated for $5 \mathrm{~s}$ and the plates were placed in the incubator. Excystment was monitored for $5 \mathrm{~d}$, until nearly all cysts from both treatments had germinated.

Maturation of cysts in fecal pellets. We examined the possibility that cyst maturation proceeds differently in cysts enclosed in, and outside of, fecal pellets, by feeding newly formed Scrippsiella lachrymosa cysts to Capitella sp. and successively incubating cysts from the resulting fecal pellets throughout the maturation period. S. lachrymosa cysts were harvested 1 wk after onset of encystment. Thus, cyst age varied between 1 and $7 \mathrm{~d}$, since cyst formation proceeded over a period of $1 \mathrm{wk}$. In the following we will refer to all cysts produced within this interval as 1 wk old or newly formed cysts. Cysts were added to petri dishes 
containing 10 individuals of Capitella sp. After 12 h, clusters of fecal pellets were harvested into cryovials and resuspended in $1 \mathrm{ml}$ of filtered Vinyard Sound water. Likewise, we prepared vials containing $1 \mathrm{ml}$ cyst suspension from a petri dish without worms to provide the cysts for the control. All cryovials were wrapped in aluminium foil and stored at $4^{\circ} \mathrm{C}$. Beginning from the first week of cold, dark storage, 3 replicate pellet and control vials were prepared for germination experiments in weekly intervals for $5 \mathrm{wk}$. Contents of the vials were sonicated and 30 cysts of each treatment were isolated into culture wells. The plates were placed in an incubator set to a temperature of $15^{\circ} \mathrm{C}$ and checked once a week for germinated cysts. The experiment was terminated 2 wk after the last isolations, when all cysts had germinated from all successive isolations.

Statistical analyses. Germination data were analyzed by means of binomial logistic regression. We tested the main effects of gut passage and pelletization on cyst germination. We also tested whether ingestion by particular worms affected the proportion of cysts that germinated. The significance of individual variables was examined by performing the logistic regression with and without the variable of interest. The drop-in-deviance test (Ramsay \& Schafer 2002) was performed to test whether the variable of interest significantly improved the model fit. These analyses were performed using SPSS software. To assess the power of our statistical analyses, we calculated beta error using Power-and-Precision software (Biostat, Inc.). Effects of sonication on germination over 4 observation periods were tested by 2-way ANOVA, following arcsinesquare-root transformation of the proportional germination data.

\section{RESULTS}

Preliminary tests indicated that sonication did not affect cyst germination (ANOVA, $\left(F_{1,40}=0.26, \mathrm{p}=\right.$ 0.61). Cysts required at most $7 \mathrm{~d}$ of incubation in $\mathrm{f} / 2$ medium to germinate (Fig. 1). Thus, comparisons of germination success for all subsequent experiments were made on Day 7 of incubation.

There was no significant effect on germination due to gut passage in Streblospio benedictii (Fig. 1a, $\chi^{2}{ }_{[2]}$ $=0.43, \mathrm{p}=0.8$ ), Capitella sp. (Fig. $1 \mathrm{~b}, \chi^{2}{ }_{[2]}=4.33, \mathrm{p}=$ 0.115 ) or Polydora cornuta (Fig 1c, $\chi_{[2]}^{2}=2.86, \mathrm{p}=$

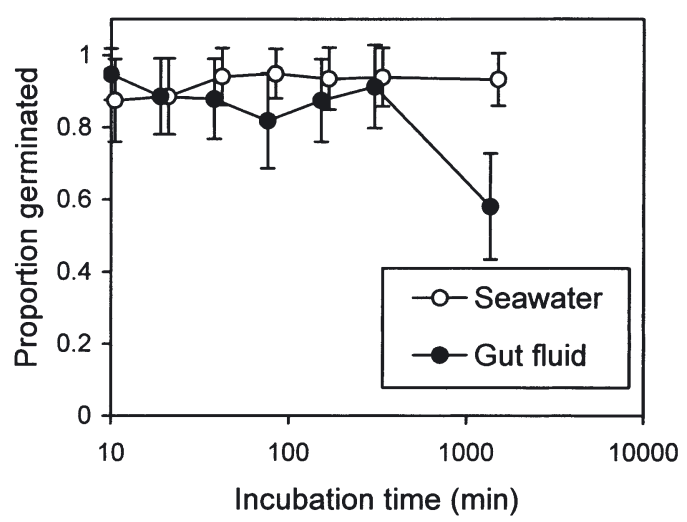

Fig. 2. Scrippsiella lachrymosa. Germination of cysts following incubation in Arenicola marina digestive fluid and seawater. Error bars indicate $95 \%$ confidence intervals. Locations of points along the abscissa were spread to distinguish error bars from different treatments 
0.24). Given $\alpha=0.05$, these experiments were capable of detecting a 30 to $40 \%$ difference in proportion of germinated cysts with a $\beta$ error of $20 \%$. There was little difference in germination between cysts incubated in seawater and Arenicola marina digestive fluids for up to $5 \mathrm{~h}$ (Fig. 2). However, by $24 \mathrm{~h}$, the proportion of cysts germinated was significantly lower for those incubated in digestive fluid compared to those incubated in seawater $\left(\chi_{[1]}^{2}=15, \mathrm{p}<\right.$ 0.0001).

Encapsulation of cysts in the fecal pellets of Streblospio benedicti did not significantly alter germination (Fig. $3, \chi_{[11]}^{2}=1.6, p=0.21$ ). The $\beta$ error for this experiment was less than $20 \%$ for detecting a $10 \%$ difference in germination, given $\alpha=0.05$. However, germination rates were higher for cysts encapsulated in Capitella sp. fecal pellets than for those removed from pellets (Fig. 3). Results of binomial logistic regression indicated significant differences in germination between cysts in intact Capitella sp. pellets and from disaggregated pellets, and among different worms $\left(\chi^{2}{ }_{[8]}=36.5, p<0.0001\right)$. The effect of pelletization alone was also significant (drop in deviance test, $\left.\chi_{[1]}^{2}=7.73, p=0.0054\right)$. Although a higher proportion of cysts germinated in intact Capitella sp. pellets, it took approximately $2 \mathrm{~d}$ longer for motile cells to appear in the culture wells (Fig. 4). The interaction between pelletization and incubation time was highly significant for both Capitella sp. (Fig $4 \mathrm{~b}, \chi_{[1]}^{2}=$ 24.5, $\mathrm{p}<0.0001$ ) and $S$. benedicti (Fig $4 \mathrm{a}, \chi_{[1]}^{2}=15.5$, $\mathrm{p}<0.0001)$. In the maturation experiment, there appears to be a greater proportion of germination of cysts in Capitella sp. pellets in the first few weeks, similar to results of the previous experiment (Fig. 5), but this apparent effect was not significant over the

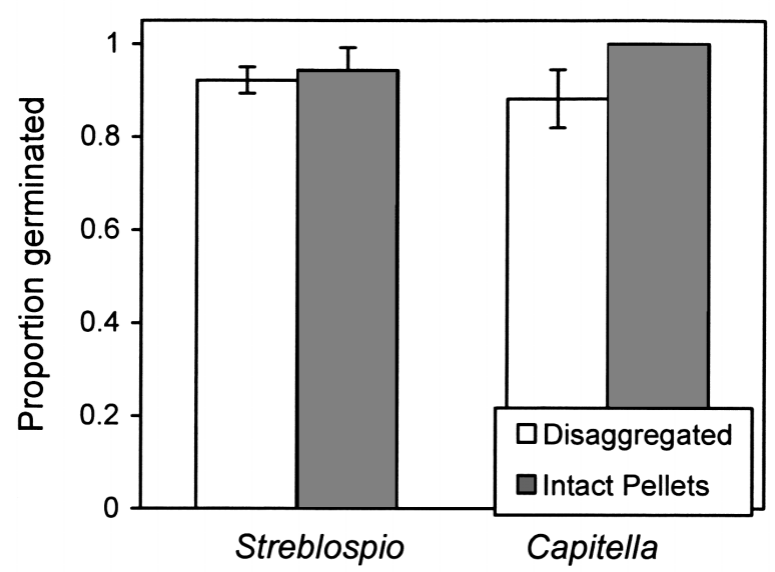

Fig. 3. Scrippsiella lachrymosa. Germination of cysts from intact and disaggregated fecal pellets of Streblospio benedicti and Capitella sp. Error bars indicate 95\% confidence intervals

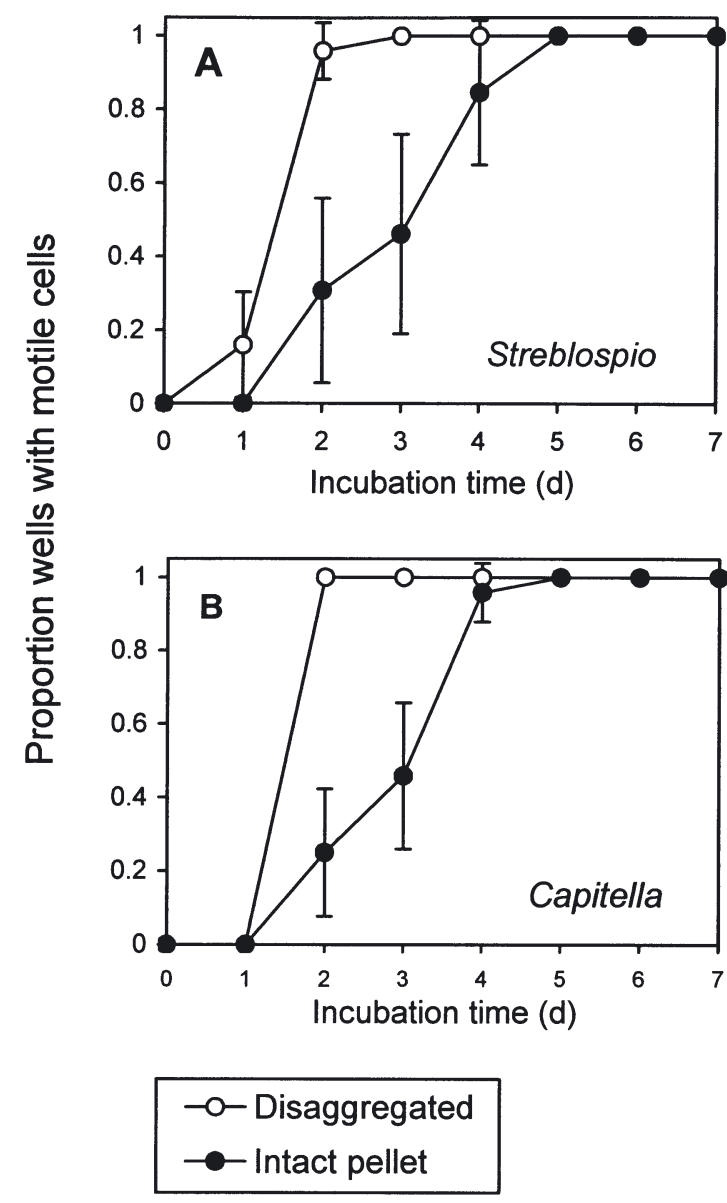

Fig. 4. First appearance of motile cells in culture wells containing intact and disaggregated fecal pellets of Streblospio benedicti (A) or Capitella sp. (B). Error bars indicate 95\% confidence intervals

entire duration of the experiment $\left(\chi^{2}{ }_{[2]}=0.483, \mathrm{p}=\right.$ 0.79 ). This experiment had an overall power of $80 \%$ $(\beta=20 \%)$ for detecting an $8 \%$ difference in proportion of cysts germinating.

\section{DISCUSSION}

Our findings indicate that resting cysts of Scrippsiella lachrymosa are resistant to digestion by depositfeeding polychaetes. Our experiments also provide evidence for the first time, to our knowledge, that cyst germination is not substantially reduced by pelletization, either with respect to actual excystment or to the release of motile germling cells through the pellet membranes. In fact, being enclosed in a fecal pellet seems to be favorable for germination, as evidenced by increased rates of excystment in intact pellets of Capitella sp. 


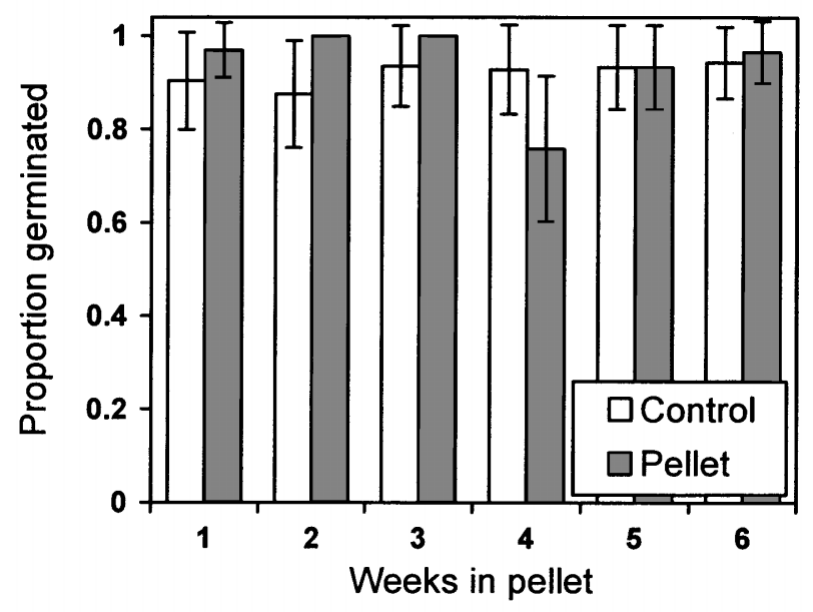

Fig. 5. Scrippsiella lachrymosa. Germination of cysts from Capitella sp. fecal pellets following incubation periods of different lengths within the pellets. Error bars indicate 95\% confidence intervals

Cysts of Scrippsiella lachrymosa were ingested by all 3 polychaete species used in this study. Depositfeeding polychaetes in general have gut-passage times of $<1 \mathrm{~h}$, suggesting that their digestive enzymes and surfactants, though intensely active (Mayer et al. 1997), have little time to act on the complex and resistant cyst walls. Cysts isolated from feces and pellets looked completely normal, showing no signs of mechanical damage or dissolution of their calcareous covering. Even after prolonged in vitro exposure to the gut fluids of Arenicola marina, the morphology of the cysts remained unaffected. One might have expected dissolution of the crystals typically covering the cyst walls. However, the $\mathrm{pH}$ regime prevailing in polychaete guts is generally neutral (Plante \& Jumars 1992), and biochemical processes apparently are unable to dissolve the Ca deposits on the walls. Our observations suggest that, though falling into the size range of potential food particles (Sanders et al. 1962, Self \& Jumars 1988), cysts don't seem to be directly utilized as a food source by the 3 tested polychaetes. Similarly, Persson \& Rosenberg (2003) concluded from grazing experiments with various taxonomic groups of benthic deposit feeders that polychaetes did not feed on dinoflagellate cysts, in contrast to bivalves and echinoderms, which significantly reduced the number of cysts offered to them as food. Perhaps cyst predators require crushing mouthparts or other forms of mechanical penetration to destroy the cysts and digest the contents.

Apparently, enzymes or other chemical compounds cannot penetrate the walls of cysts such that the protoplast would be damaged or physiologically impaired, at least not over time-scales of minutes or hours realistic for 1 to a few gut passage times (e.g. Forbes \& Lopez 1990, Ahrens 2001). Our findings agree with results from ingestion studies of cysts of Scrippsiella trochoidea and Alexandrium spp. (Ichimi \& Montani 2001, Tsujino et al. 2002). Those studies, however, were performed with cysts of unknown history, making it difficult to isolate the effect of gut passage from the many other influences cysts are likely to experience when resting in the sediment. Marcus (1984), who conducted controlled laboratory experiments similar to ours with zooplankton resting stages, reported that the dormant eggs of marine copepods were nearly unaffected by polychaete gut passage.

As our experiments with digestive fluids of Arenicola marina indicate, cysts must be exposed to digestive fluids for more than $6 \mathrm{~h}$ before their germination would be significantly reduced. Theoretically, repeated ingestions amounting cumulatively to such a long gut residence time might ultimately decrease the germination potential of a cyst. It has been reported that enzymes can access resistant pollen grains during gut passage through the germination pore without prior disruption of the resistant pollen wall (Grant 1996). Like pollen, cysts have sutures (Dale 1983) in their walls that might make them susceptible to enzyme activity during prolonged exposure to digestive fluids. However, it is relatively unlikely that the same cysts would be ingested more than a few times, particularly if bound in pellets, since worms tend to select free particles and particles of low density before reingesting a pellet (Taghon et al. 1984). If the residence time of cysts is longer in guts of larger worms (Forbes \& Lopez 1987, Ahrens et al. 2001), response to gut passage might be different than in the present study, where polychaete individuals were small $(<1 \mathrm{~cm})$. Large macrofaunal polychaetes were, for example, used in the study of Giangrande et al. (2002), who found, in contrast to all other available reports, that germination of cysts was reduced after polychaete gut passage. However, the results of Giangrande et al. (2002) may also indicate the potential importance of timing of gut passage during the maturation period, similar to other germination-controlling factors (Montresor \& Marino 1996), as cysts used in their study were still in an early stage of maturation. The results of our gut-fluid incubation experiments clearly indicate that mature cysts may be resistant to extremely long gut-passage times.

Encapsulation of cysts in fecal pellets has so far been considered a loss to the germination potential of dinoflagellate cyst populations (Ichimi \& Montani 2001, Tsujino et al. 2002). This hypothesis is mainly based on the assumption that conditions prevailing inside the pellet (low light and oxygen) are unfavor- 
able and would prevent germination. Furthermore, it is assumed that even if a cyst were to germinate, it would be impossible for the germling cell to break through the surrounding mucous membrane. Thus, we were surprised to find that all cysts had germinated inside the pellets of both Streblospio benedicti and Capitella sp. and motile populations were proliferating in the culture wells. Apparently the conditions inside the polychaete pellet, including reduced irradiance levels and low oxygen, do not constrain germination. Encapsulation in a pellet may even be advantageous, as the enhanced germination we observed in the pellets of Capitella sp. suggests. Fecal pellets often contain relatively high concentrations of organic matter and exhibit high rates of denitrification in their anoxic interiors (Henriksen et al. 1983). It is possible that cysts benefit from the degradation processes inside the pellets and the resulting release of nutrients. According to Rengefors et al. (1996), dinoflagellate cysts are able to take up and accumulate nutrients during their resting period. If inorganic nutrients are abundant inside fecal pellets, they may be taken up by the cysts and used to prepare for germination.

Given that the environment in fecal pellets may be favorable for cyst germination, it could be hypothesized that if a cyst were to spend a longer fraction of its dormancy in a pellet, it might become ready for excystment sooner. We tested this hypothesis, but did not find significant evidence of such an effect. Although excystment was generally enhanced in cysts that had been stored in pellets, their maturation period was neither shorter nor longer compared to cysts from the controls. Presumably, an endogenous rhythm that is largely independent of external influences (cf. Anderson \& Keafer 1987) governs maturation and overrides the potentially favorable effect of pellet encapsulation. The appearance of motile cells outside the pellets indicates that germlings are able to overcome the physical barrier of the pellet membrane. Escaping from the membrane may take longer, as cells occur later in culture wells containing intact pellets compared to wells with disaggregated pellets. However, motile cells are released, and thus we can conclude that encapsulation of cysts in polychaete pellets should not reduce the seeding potential of a benthic cyst population as previously assumed.

Provided that pellets are egested on the sediment surface, cysts from polychaete fecal pellets could seed a new vegetative dinoflagellate population. Theoretical models of bioturbation and pelletization (Jumars et al. 1981) indicate that pelletization can increase the residence time of particles in surficial sediments, favoring germination.
The fate of cysts as well as fecal pellets, however, depends on the structure of, and feeding modes within, the respective benthic community. In sediments with high abundances of large surface-feeding polychaetes, for example, downward mixing caused by worm activity may deposit surface material, including cysts, at depth (Levin et al. 1997, Shull \& Yasuda 2001), where excystment is most likely prevented by dark anoxic conditions (Keafer et al. 1992). Some benthic habitats, on the other hand, are dominated by subsurface-feeding species that defecate on the surface, such as Capitella sp. or Mediomastus ambiseta. Their activity causes downward advection of surface deposits to the feeding zone, subsequent ingestion and redeposition through pellet egestion to the sediment surface. Particles (including cysts) that accumulate in such areas could consequently be concentrated in fecal pellets on the surface or within the uppermost $2 \mathrm{~cm}$ of the sediment, where favorable oxygen levels and other germination cues could trigger excystment. This mechanism of cyst retention in the 'germination layer' would contribute to the seeding success of the cyst population and, hence, favour dinoflagellate bloom initiation. Our findings will also considerably simplify bioturbation models that aim to predict dinoflagellate cyst transport in the sediment, since the minimal effects of gut passage and pelletization on cyst viability allow this level of complexity to be disregarded.

Acknowledgements. This study was supported by grants from the German Academic Exchange Service, the Academy of Finland (A.K.), from NOAA NA96OP0099 (D.H.S.) and OCE9808173 from NSF (D.M.A.). This is contribution number 75 of the U.S. ECOHAB Program, sponsored by NOAA, NSF, EPA, NASA, and ONR, and contribution no. 11015 from the Woods Hole Oceanographic Institution.

\section{LITERATURE CITED}

Ahrens MJ, Hertz J, Lamoureux EM, Lopez GR, McElroy AE, Brownawell BJ (2001) The role of digestive surfactants in determining bioavailability of sediment-bound hydrophobic organic contaminants to two deposit-feeding polychaetes. Mar Ecol Prog Ser 212:145-157

Alberstsson J, Leonardsson K (2001) Deposit-feeding amphipods (Monoporeia affinis) reduce the recruitment of copepod nauplii from benthic resting eggs in the northern Baltic Sea. Mar Biol 138:793-801

Anderson DM, Keafer BA (1987) An endogenous annual clock in the toxic marine dinoflagellate Gonyaulax tamarensis. Nature 325:616-617

Anderson DM, Wall D (1978) Potential importance of benthic cysts of Gonyaulax tamarensis and Gonyaulax excavata in initiating toxic dinoflagellate blooms. J Phycol 14:224-234

Anderson DM, Aubrey DG, Tyler MA, Coats DW (1982) Vertical and horizontal distribution of dinoflagellate cysts in sediments. Limnol Oceanogr 27:757-765

Binder BJ, Anderson DM (1987) Physiological and environ- 
mental control of germination in Scrippsiella trochoidea (Dinophyceae) resting cysts. J Phycol 23:99-107

Blanco J (1985) Cyst production in four species of neritic dinoflagellates. J Plankton Res 17:165-182

Caceres CE, Hairston NG Jr (1998) Benthic-pelagic coupling in planktonic crustaceans: the role of the benthos. Archiv Hydrobiol Spec Iss, Adv Limnol 52:163-174

Cammen LM (1980) Ingestion rate: an empirical model for aquatic deposit feeders and detritivores. Oecologia 44: $303-310$

Dale B (1983) Dinoflagellate resting cysts: 'benthic plankton'. In: Fryxell GA (ed) Survival strategies of the algae. Cambridge University Press, Cambridge, p 69-136

Forbes TL, Lopez GR (1987) The allometry of deposit feeding in Capitella sp. I. (Polychaeta: Capitellidae): the role of temperature and pellet weight in the control of egestion. Biol Bull 172:187-201

Forbes TL, Lopez GR (1990) Ontogenetic changes in individual growth and egestion rates in the deposit-feeding polychaete Capitella sp. 1. J Exp Mar Biol Ecol 143: 209-220

Giangrande A, Montresor M, Cavallo A, Licciano M (2002) Influence of Naineris laevigata (Polychaeta: Orbiniidae) on vertical grain size distribution, and dinoflagellate resting stages in the sediment. J Sea Res 47:97-108

Grant BR (1996) Pollen digestion by Darwin's finches and its importance for early breeding. Ecology 77:489-499

Hansson LA (1996) Algal recruitment from lake sediments in relation to grazing, sinking, and dominance patterns in the phytoplankton community. Limnol Oceanogr 41: 1312-1323

Head RM, Jones RI, Bailey-Watts AE (1999) An assessment of the influence of recruitment from the sediment on the development of planktonic populations of cyanobacteria in a temperate mesotrophic lake. Freshw Biol 41:759-769

Heiskanen AS (1993) Mass encystment and sinking of dinoflagellates during a spring bloom. Mar Biol 116: 161-167

Henriksen, KM, Rasmussen B, Jensen A (1983) Effect of bioturbation on microbial nitrogen transformations in the sediments and fluxes of ammonium and nitrate to the overlying water. Ecol Bull 35:193-205

Huber G, Nipkow F (1923) Experimentelle Untersuchungen über Entwicklung und Formbildung von Ceratium hirundinella O.F. Müller. Flora 116:114-215

Ichimi K, Montani S (2001) Effects of deposit feeder ingestion on the survival and germination of marine flagellate cysts. Fish Sci 67:1178-1180

Imai I, Itakura S, Itoh K (1991) Life cycle strategies of the red tide causing Chatonella (Raphidophyceae) in the Seto Inland Sea. Mar Poll Bull 23:165-170

Ishikawa A Taniguchi A (1996) Contribution of benthic cysts to the population dynamics of Scrippsiella spp. (Dinophyceae) in Onagawa Bay, northeast Japan. Mar Ecol Prog Ser 140:169-178

Itakura S, Imai I, Itoh K (1997) 'Seed bank' of coastal planktonic diatoms in bottom sediments of Hiroshima Bay, Seto Inland Sea, Japan. Mar Biol 128:497-508

Jumars PA, Nowell ARM, Self RFL (1981) A simple model of flow-sediment-organism interaction. Mar Geol 42: 155-172

Keafer BA, Buesseler KO, Anderson DM (1992) Burial of living dinoflagellate cysts in estuarine and nearshore sediments. Mar Micropaleontol 20:147-161

Kearns CM, Hairston NG Jr, Kessler DH (1996) Particle transport by benthic invertebrates: its role in egg bank dynamics. Hydrobiologia 332:63-70
Kokinos JP, Anderson DM (1995) Morphological development of resting cysts in cultures of the marine dinoflagellate Lingulodinium polyedrum (= L. machaerophorum). Palynology 29:143-166

Kremp A (2000) Distribution, dynamics and in situ seeding potential of Scrippsiella hangoei (Dinophyceae) cyst populations from the Baltic Sea. J Plankton Res 22:2155-2169

Kremp A, Anderson DM (2000) Factors regulating germination of resting cysts of the spring bloom dinoflagellate Scrippsiella hangoei from the northern Baltic Sea. J Plankton Res 22:1311-1327

Levin LA, Blair N, DeMaster DJ, Plaia G, Fornes W, Martin C, Thomas C (1997) Rapid subduction of organic matter by maldanid polychaetes on the North Carolina slope. J Mar Res 55:595-611

Lewis J, Harris ASD, Jones KJ, Edmonds RL (1999) Long-term survival of marine planktonic diatoms and dinoflagellates in stored sediment samples. J Plankton Res 21:343-354

Luckenbach MW, Orth RJ (1999) Effects of a deposit feeding invertebrate on the entrapment of Zostera marina L. seeds. Aquat Bot 62:235-247

Marcus NH (1984) Recruitment of copepod nauplii into plankton: importance of diapause eggs and benthic processes. Mar Ecol Prog Ser 15:47-54

Mayer LM, Self RFL, Jumars PA, Findlay RH, Chen Z, Sampson S (1997) Digestive environments of benthic macroinvertebrate guts: enzymes, surfactants, and dissolved organic matter. J Mar Res 55:1-30

McQuoid MR (2002) Pelagic and benthic environmental controls on the spatial distribution of a viable diatom propagule bank on the Swedish west coast. J Phycol 38: 881-893

Montani S, Ichimi K, Meksumpun S, Okaichi T (1995) The effects of dissolved oxygen and sulfide on germination of the cysts of some different phytoflagellates. In: Lassus P, Arzul G, Le Denn EE, Gentien P, Marcaillou-LeBaut P (eds) Harmful marine algal blooms. Lavoisier, Paris, p 627-632

Montresor M, Marino D (1996) Modulating effect of cold-dark storage on excystment in Alexandrium pseudogonyaulax (Dinophyceae). Mar Biol 127:55-60

Nuzzo L, Montresor M (1999) Different excystment patterns in two calcareous cyst producing species of the dinoflagellate genus Scrippsiella. J Plankton Res 21:2009-2018

Olli K, Anderson DM (2002) High encystment success of the dinoflagellate Scrippsiella cf. lachrymosa in culture experiments. J Phycol 38:145-156

Persson A (2000) Possible predation of cysts - a gap in the knowledge of dinoflagellate ecology? J Plankton Res 22: 803-809

Persson A, Rosenberg R (2003) Grazing on marine dinoflagellate cysts by benthic deposit feeding animals. Harmful Algae 2:43-50

Plante C, Jumars P (1992) The microbial environment of marine deposit-feeder guts characterized via microelectrodes. Microb Ecol 23:257-277

Ramsay F, Schafer D (2002) The statistical sleuth, 2nd edn. Duxbury Press, Pacific Grove

Rengefors K, Anderson DM (1998) Environmental and endogenous regulation of cyst germination in two freshwater dinoflagellates. J Phycol 34 568-577

Rengefors K, Anderson DM, Petterson K (1996) Phosphorus uptake by resting cysts of the marine dinoflagellate Scrippsiella trochoidea. J Plankton Res 18:1753-1765

Rhoads DC, Young DK (1970) The influence of deposit feeding organisms on sediment stability and community structure. J Mar Res 28:150-178 
Sanders HL, Goudsmit EM, Mills EL, Hampson GE (1962) A study of the intertidal fauna of Barnstable Harbor, Massachusetts. Limnol Oceanogr 7:63-79

Self RFL, Jumars PA (1988) Cross-phyletic patterns of particle selection by deposit feeders. J Mar Res 46:119-143

Sgrosso S, Esposito F, Montresor M (2001) Temperature and day length regulate encystment in calcareous cystforming dinoflagellates. Mar Ecol Prog Ser 211:77-87

Shull DH, Mayer LM (2002) Dissolution of particle-reactive radionuclides in deposit-feeder digestive fluids. Limnol Oceanogr 47:1530-1526

Shull DH, Yasuda M (2001) Size-selective downward particle transport by cirratulid polychaetes. J Mar Res 59: 453-473

Editorial responsibility: Otto Kinne (Editor),

Oldendorf/Luhe
Smetacek V (1985) Role of sinking in diatom life history cycles: ecological, evolutionary and geological significance. Mar Biol 84:239-251

Ståhl-Delbanco A, Hansson LA (2002) Effects of bioturbation on recruitment of algal cells from the 'seed bank' of lake sediments. Limnol Oceanogr 47:1836-1843

Taghon GL, Nowell ARM, Jumars PA (1984) Transport and breakdown of fecal pellets: biological and sedimentological consequences. Limnol Oceanogr 29:64-72

Tsujino M, Kamiyama T, Uchida T, Yamaguchi M, Itakura S (2002) Abundance and germination capability of resting cysts of Alexandrium spp. (Dinophyceae) from fecal pellets of macrobenthic organisms. J Exp Mar Biol Ecol 271:1-7

Submitted: April 15, 2003; Accepted: September 30, 2003

Proofs received from author(s): November 24, 2003 